\title{
Analysis of Culture and Buyer Behavior in Chinese Market
}

\author{
Yan Luo \\ School of Management \\ Tianjin University \\ \#92 Weijin RD, Nankai District, Tianjin 300070, China \\ Email: iamcarolluo@yahoo.com.cn
}

\begin{abstract}
Culture is the most basic cause of a person's wants and behavior. Country, like China, who has such a long history, has rich culture background. So it is very critical for international cooperates who want to do business in China to know about Chinese culture and how it works to buyers' behavior. Starting from Chinese culture in Marketing context, this paper discusses how culture influence buyers' behavior in Chinese Market.
\end{abstract}

Keywords: Culture, Buyers' behavior, Chinese market

\section{Culture in Marketing Issues}

\subsection{Definition of culture}

Culture, originally derived from Latin cultura which means "tending or "maintaining", has multiple and diverse definitions nowadays. Each of them has its own aspects. Kroeber and Kluckhohn (1967) based on these various categories of concept, suggest the following comprehensive definition: "Culture consists of patterns, explicit and implicit, of and for behavior acquired and transmitted by symbols constituting the distinctive achievement of human groups, including their embodiments in artifacts; the essential core of culture consists of traditional (historically derived and selected) ideas and especially their attached values; culture systems may, on one hand, be considered as products of action, on the other as conditioning elements of further action."

\subsection{Levels of culture}

People define culture through different categories, including origin, history, religion, language, etc (Huntington, 1996). In business and marketing context, there are a great number of other cultural dimensions, such as organizational or professional culture becomes relevant (Schein 1984).

The various cultural conceptions can be regarded as different levels of the same basic concept. (Srnka 2004), distinguished four such levels:

- Supra-Culture, shared by nations with similar economic systems and development, ethnicity, religion, etc.

- Macro-Culture, shared by people of the same nationality, origin or country of residence

- Meso-culture, shared by groups or communities, e.g. a professional group or industry, within a macro-culture

- Micro-culture, shared by smallest social collectivities, e.g. the organization. Family or clan (especially for Eastern counties).

These culture levels cannot be considered isolated from each other; they are intertwined and influence each other.

\subsection{Wider and closer culture environment}

While supra- and macro-cultural factors represent the wider cultural environment, meso- and micro-cultural forces constitute the closer cultural environment, this distinction is significant because the two cultural environments differ in the way in which values are learned, as well $\mathrm{s}$ in value endurance and their impact on behavior. The acquisition of values from the wider cultural environment takes place through socialization in early childhood (by family and school), and is updated later via mass media. Groups in the closer environment (particularly peers), on the other hand, exert social influence in day-to-day interactions. Continuing adult development had particularly been linked to educational and work experiences (Trevino, 1986). 
Levels of Culture: A Marketing Perspective

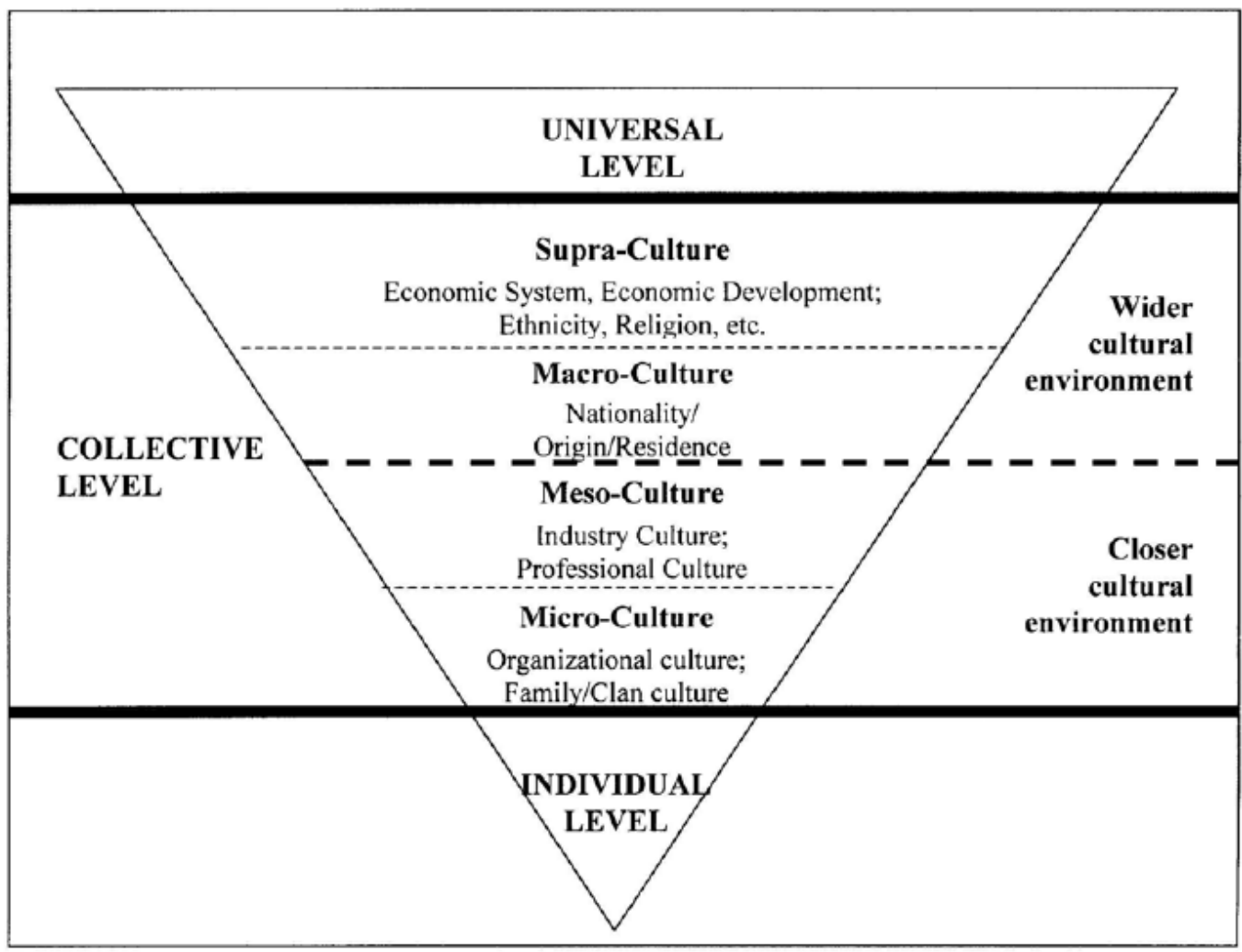

\section{The Buyer behavior ---- decision making processes}

Research suggests that customers go through a five-stage decision-making process in any purchase. This is summarized in the diagram below:

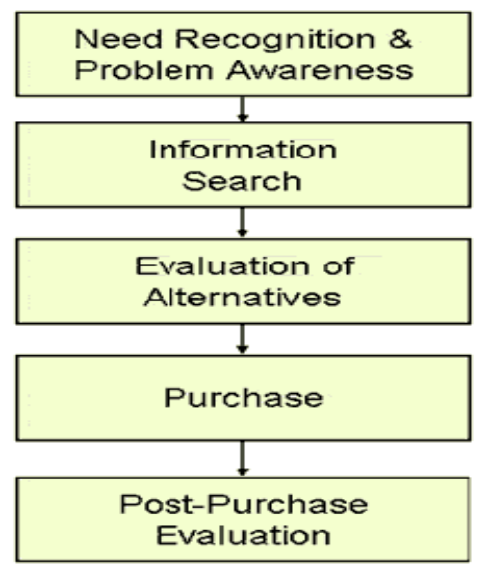

This model is important for anyone making marketing decisions. It forces the marketer to consider the whole buying process rather than just the purchase decision (when it may be too late for a business to influence the choice!)

The model implies that customers pass through all stages in every purchase. However, in more routine purchases, customers often skip or reverse some of the stages.

The buying process starts with need recognition. At this stage, the buyer recognizes a problem or need or responds to a marketing stimulus. For example, you feel hanger, then you have a need to eat. Or you pass Starbucks and are attracted by the aroma of coffee and chocolate muffins.

An "aroused" customer then needs to decide how much information (if any) is required. If the need is strong and there is a product or service that meets the need close to hand, then a purchase decision is likely to be made there and then. If not, the process of information search begins.

A customer can obtain information from several sources: 
- Personal sources: family, friends, neighbors etc

- Commercial sources: advertising; salespeople; retailers; dealers; packaging; point-of-sale displays

- Public sources: newspapers, radio, television, consumer organizations; specialist magazines

- Experiential sources: handling, examining, using the product

The usefulness and influence of these sources of information will vary by product and by customer. Research suggests that customers value and respect personal sources more than commercial sources (the influence of "word of mouth"). The challenge for the marketing team is to identify which information sources are most influential in their target markets.

In the evaluation stage, the customer must choose between the alternative brands, products and services.

\section{Culture's role in Chinese market}

\subsection{Chinese Culture in Marketing Context}

China, as Eastern Dragon, has more than 5,000-year history and rich culture which full of mystery and are fresh for Western people. These cultures have been passing generation by generation so that has big influence to people's behavior, which also include buyer behaviors.

\subsubsection{Confucianism (Kongzi, or "Master Kong,")}

Confucius lived in China during the latter half of the Zhou dynasty (eleventh century-256 B.C.E.). As a philosopher and teacher, Master Kong influences far more people today through classic writings, such as the Analects (Lunyu), than he did during his lifetime. He created a philosophy that later became a major influence in the organization of Imperial Age China, and was adopted and modified in other countries such as Korea, Japan, and Vietnam.

Confucius emphasized principles for self-guidance. The key to producing a harmonious life, he wrote, is in how we treat others-our ancestors, leaders, parents, spouses, neighbors, and friends. To Confucius, a person becomes noble not by birth but by developing the five virtues of humanity or benevolence (ren), righteousness (yi), proper conduct (li), wisdom (zhi), and trustworthiness (xin). The most important Confucian virtue is filial piety (xiao), the respect and obedience of children toward their parents ---- for when all relationships between family members are in order, then society will also be orderly.

Two other concepts that were predominant in Confucius's worldview were Tian (Heaven) and Dao (Way). His heaven represented a celestial power connected with the will of mighty ancestors, such as the widely known Yao, Shun, and Yü. The Way, on the other hand, constituted a natural path for humanity. Whereas Heaven emphasized choice, the Way required a yielding heart-mind (xin); both were crucial for achieving harmony in the earthly realm.

\subsubsection{Taoism (Laozi "Old Master,")}

The concept of Dao is more often associated with the figure Laozi and the classic Dao de Jing (The Book of the Way and Its Power) than with Confucius. It is not certain whether they were contemporaries. Their philosophies, though, are like two sides of a coin. Laozi emphasized harmony with the Dao-a referent to something that cannot be named-in order to achieve balance in life. To assist this process, Laozi taught his followers the concepts of nonaction (wu wei) and shade and light (yin/yang-primordial, dynamic balancing of opposites). The principle of non-action meant that one should discern the natural course of things and cooperate with that movement. Thus, if a person was good at making clothes, he or she shouldn't become a cook. The concept of yin/yang reminded Laozi's students to look for the balancing forces of opposites and learn how to cooperate with and embody them. The teachings of Laozi and Confucius were not incorporated into a religious movement until the Han dynasty (206 B.C.E.-220 C.E.). The result was a mix of philosophy and religion. Over the centuries that followed, both Confucianism (Rujiao-the teachings of the scholars) and Daoism (Daojiao-the teaching of the Way) developed elaborate rituals and sacred writings. To this day the philosophies of Laozi and Confucius, and the religious movements their lives and teachings inspired, exist in vibrant forms in Chinese, Korean, Japanese, and Vietnamese culture as well.

\subsubsection{Sub-Cultures}

\section{"Guanxi" Culture ---- Relationship Issues}

Guanxi culture in China can be derived from ancient Chinese philosophies, especially Confucianism. Although the word "guanxi" is not found in Confucian classics, the word "lun" is used instead, which is regarded as the root of guanxi (King, 1991). As Confucian mentioned, in China, a relation0oriented society, one was a socially depended being, which made it imperative to know one's social position, to fulfill one's duties and obligations, and to observe the appropriate moral standards.

Guanxi can be defined as an informal, particularistic personal connection between two individuals who are bounded by 
an implicit psychological contract to follow the social norm of guanxi such as maintaining a long-term relationship, mutual commitment, loyalty, and obligation (Chen and Chen, 2004).

Guanxi can refer either to the state of two or more parties being connected or the connected parties themselves. As a state of being connected, it is either in existence or not, good or bad, close or distant, deep or shallow, in tension or in harmony. In reference to the actual parties involved, a guanxi can be individual or an organization, as a dyad or as a network. Guanxi also can be described as guanxi-related activities, such as "pull guanxi" referring to actions of initiating and establishing a connection, and "walk guanxi" meaning to use connections to achieve specific purposes, other frequently used verbs include building, developing, consolidating, maintaining, breaking and so on.

\section{Collectivism}

Collectivism refers to the extent to which individuals are integrated into groups and form their judgments based on group norms (Hofstede and Bond, 1988). Members of collectivism acknowledge their interdependent natures and obligations to the group. They place relatively greater importance on the group's needs and norms than individualism (Triandis, 1990).

Chinese people, as typical collectivist, are often motivated by norms and duties imposed by the in-group, and try to emphasize their connectedness with in-group. The tendency to focus on group preferences and group harmony leads to an ability to repress internal (personal) attributes in certain settings (Kacen \& Lee, 2002). Collectivists prefer to be the same or similar with others in the group. They are easily impacted by consensus or public voice, and care a lot about the other people's opinion about them.

"Mianzi" ---- "Face” Issues

Mianzi or "face", from the social-psychological point of view, refers to an individual's reputation or value in the eyes of others. Related to the collectivism and Guanxi issues, never losing face is very important for Chinese people. Mianzi - related activities are kinds of impression decoration behaviors which are done on purposely to make a certain impression to others. In Chinese culture and Public relationship, "mianzi" is an essential element. Some items using in this area reflects some of this culture, such as "lose face" (be hurt by getting lower value from others), "no mianzi" (not be recognized as expecting), "have Mianzi" (be considered in very good way), "give face" (make the others feel satisfactory in recognition or reputation issues), etc.

\subsection{Chinese culture's role in buyer behaviors}

The consumer buying process is consistent across cultures. Culture influences each step of decision making process. According to Chinese culture, Chinese buyer behavior performs the following characteristics:

\subsubsection{Need recognition \& problem awareness}

Both Confucianism and Taoism focus on family's value to an individual. So being educated in this way, Chinese people have very deep concept of family, which is also reflected on their purchasing behaviors. For a typical Chinese family, the most important characters are ages, such as parents. They are old, and contribute most of their lives for the family. So they get the most respect in a family. But on the other hand, Chinese culture also emphasizes on "root" ---generation continuation. Children are looked as the future of everybody in the family, and are put a variety of expectations. In China, other than old parents, children gain a crucial position in a family. As a result, during the process of identifying needs, ages and kids have extremely priority.

Education investment is a typical example in this case. In order to help their children have a bright future, parents could invest as much as possible in education. For most of the Chinese family, kids' education need is the first need of all. Health care products for ages, kids' products are also recognized as big needs.

\subsubsection{Information search}

Although, as mentioned above, there are a bunch of ways to gain information, such as personal sources, commercial sources, public sources, and experiential sources, Chinese customers are more willing to accept information from their acquaintance ---- words of mouth.

Collectivism plays very important roles in it. Because of collectivism, Chinese consumers prefer to being the same with others in the group. Being accepted by others is important for them. That's one of the main reasons why Chinese like to find information from their friends, family members, and other familiar people. Whatever they suggest is whatever they accept. In this way, conformity can be realized. Nobody is special, nobody can be blamed.

\subsubsection{Evaluation of alternative and purchase}

"Mianzi" and "Guanxi" cultures influence buyer behavior a lot in China.

In terms of "Mianzi" issue, Chinese like to be "have Mianzi". That means they expect others think them rich, generous, and have good taste, etc., no matter whether they are or not. This culture definitely promoted a luxury consumption tide 
in China. But that is an unbalanced consumption. Like some research found that the Chinese are seen as having a low level of involvement when purchases are for private consumption but a high level of involvement when they are buying products for their social or symbolic value. Since the Chinese greatly value social harmony and smoothness of relationships within the extended family, the social significance of products are highly important be it to express status, gratitude, approval or even disapproval (Jiang, 2005).

"Guanxi" culture is another factor that results in luxury consumption in China. As most of Chinese know, good relationship with others, no matter it is individual or organization, is necessary for success. According to Chinese culture, an effective way to maintain a long-term good relationship is "gifts". Together with "Mianzi" issue, "Guanxi" culture makes consumers make a good evaluation for high-scale products, and perform their purchases, even that will beyond their ability. They believe, the more expensive the gift is, the more recognition will be gained, the more "Mianzi" they will have and give, and the better relationship they'll achieve.

\subsubsection{Post-purchase evaluation}

Post-purchase evaluation is the the final stage of the decision. It is common in China for customers to experience concerns after making a purchase decision. This arises from a concept that is known as "cognitive dissonance". The customer, having bought a product, may feel that an alternative would have been preferable. In these circumstances that customer will not repurchase immediately, but is likely to switch brands next time.

The reflection of the culture's influence on this step is mainly focus on the recognition. No matter what the customers bought, no matter how much they expended, it doesn't matter. The most important thing is to be recognized. If they got the reorganization as what they expect, that would be a positive feedback. So that they are going to do repurchases. Otherwise, they will change to buy other products next time.

\subsection{New trends}

Everything is changing in this world, either does Chinese culture and buyer behaviors. Some new trends appear in China such as hi-tech chasing, and individualism trends.

Because of a long time hunger for technology in the past, Chinese are more eager for high-technology than people of other countries, especially those developed countries.

The birth control plan in China from 1979 shapes a new generation - "Dusheng" generation (the only child in a family). Comparing with their parents and people who born earlier than them who has at least one brother or sister, this new generation has totally different living situation, and furthermore build an unique perceptions to the world and behavior principles. They are a little bit spoiled, almost has no idea of sharing, self-centered. But at the same time, they are bearing such a heavy responsibility and burden their fathers never experienced.

During their purchasing behavior process, they are more individualism and want to be special. They are not so much price-sensitive. Their main buying needs are for themselves.

These new trends have already been changing buyer behaviors in China, marketer need to notice these changes and trends so that to get more shares in this big market.

\section{Conclusion}

Influenced by its long history and rich culture, Chinese are more collectivism, pay much more attention on the relationship with others and how others think about them, and focus more on family's value, comparing with western countries. Therefore, when companies try to develop Chinese market, it is necessary for them to understand this before they start. And carry out proper marketing strategy according to how these culture influent buyers' behavior in this country.

\section{References}

Briley, D., Morris, M., \& Simonson, I. (2003). Reasons as Carriers of Culture. Journal of Consumer Research, 27(9), 157-178.

Chen, X., \& Chen, C. (2004). On the Intricacies of the Chinese Guanxi: A Process Model of Guanxi Development. Asia Pacific of Management, 21, 305-324.

Huntington, S. (1996). The Clash of Civilizations, and the Remaking of World Order. New York: Simon \& Schuster.

Jiang, C. (2005). "Mianzi” Culture Promoted "Mianzi” Consumption. Yuejiang Daily, 7,16.

Kecen, J., \& Lee, J. (2002). The Influence of Culture on Consumer Impulsive Buying Behavior. Journal of Consumer Psychology 12 (2), 163-176.

King, A. (1991). Kuan-his and Network Building: A Sociological Interpretation. Daedalus 120, 63-84.

Kroeber, A. \& Kluckhohn, C. (1967). Culture-A Critical Review of Concepts and Definitions. New York: Vintage 
Books.

Mahesh, N., Ford, J, \& Latour, M. (2003). Cultural Dimensions of Switching Behavior in Importer-Exporter Relationships, Academy of Marketing Science Review.

Pavlou, P. \& Chai, L. (2002). What Drives Electronic Commerce Across Cultures? A Cross-Cultural Empirical Investigation of the Theory of Planned Behavior. Journal of Electronic Commerce Research, 3 (4), $240-253$.

Schein, E. (1984). Coming to A New Awareness of Organizational Culture. Sloan Management Review 25, 3-16.

Srnka, K. (2004). Culture’s Role in Marketer's Ethical Decision Making. Academy of Marketing Science Review 1.

[Online] Available: http://www.amsreview.org/articles/srnka01-2001.pdf.

Trevino, L. (1986). Ethical Decision Marketing in Organizations: A Person-Situation Interactionist Model. Academy of Management Review. 11(3), 601-617.

Wong, N., \& Ahuvia, A. (1998). Personal Taste and Family Face: Luxury Consumption in Confucian and Western Societies. Psychology and Marketing, 15(5), 423-441. 